\title{
Age-associated alterations in $\gamma \delta$ T-cells are present predominantly in individuals infected with Cytomegalovirus
}

\author{
Kilian Wistuba-Hamprecht ${ }^{1}$, Daniela Frasca ${ }^{2}$, Bonnie Blomberg ${ }^{2}$, Graham Pawelec ${ }^{1}$ and Evelyna Derhovanessian ${ }^{1 *}$
}

\begin{abstract}
Background: Despite the common perception that latent Cytomegalovirus (CMV) infection is usually symptom-free, emerging epidemiological evidence suggests that it may in fact be associated with higher mortality over extended follow-up. Mechanisms responsible for this potentially important effect are unclear. CMV infection is known to have a large impact on the distribution of T cell phenotypes, especially the accumulation of late-stage differentiated $C D 8^{+}$, as well as $V \delta 2^{-} \gamma \delta$ T-cells, which are the main subset of $\gamma \delta$ T-cells involved in anti-CMV immunity. Its impact on $\gamma \delta$ T-cells in the aging context is less well-defined.
\end{abstract}

Results: Here, we investigated a group of healthy individuals aged between 21 and 89 years, in order to correlate the frequency and differentiation status of $\gamma \delta$ T-cells with age. We found that these parameters were only marginally influenced by age, but were marked in people with a latent CMV infection. Thus, we observed a significant age-associated accumulation of late-differentiated T-cells within the V $\delta 2^{-}$population, but only in CMV-seropositive donors. There was also a strong trend towards reduced frequency of early-differentiated cells within the V $\delta 2^{-}$phenotype. Older people had significantly higher anti-CMV IgG titers, which in turn correlated significantly with a lower $V \delta 2^{+} N \delta 2^{-}$ratio and a shift from early- to a late-differentiated $V \delta 2^{-} T$-cell phenotype.

Conclusions: Our findings demonstrate a strong influence of CMV on $\gamma \delta$ T-cells during human ageing, similar to that observed for a $\beta$ T-cells. Differences between donors of different ages are more marked in CMV-infected individuals. The biological implications of this potent age-associated CMV-mediated immune-modulation require clarification.

Keywords: $\gamma \delta$ T-cells, Differentiation phenotype, CMV, Human ageing

\section{Background}

$\gamma \delta$ T-cells represent a minor population of approx. $5 \%$ of the whole T-cell population in healthy adult individuals. The ligands recognized by the $\gamma \delta$ receptor are yet not fully identified, but it is known that different isotypes of $\gamma \delta$ T-cell receptor (TCR) recognize common stressinduced molecules on self cells as well as structures on the surface of pathogens. The majority of $\gamma \delta$ T-cells is CD4 ${ }^{-C D} 8^{-}$, but a small population expresses CD8 [1]. $\gamma \delta$ T-cells are further grouped via their different $\delta$-chains. The majority (approximately $70 \%$ ) of $\gamma \delta$ T-cells in human blood is represented by the V $\delta 2$ receptor. The remaining

\footnotetext{
* Correspondence: evelyna.derhovanessian@klinikum.uni-tuebingen.de ${ }^{1}$ Department of Internal Medicine II, Centre for Medical Research, University of Tübingen, Tübingen, Germany

Full list of author information is available at the end of the article
}

$\gamma \delta$ T-cells in the blood mainly express the $V \delta 1$ receptor but other more rare subpopulations such as V $\delta 3, \mathrm{~V} \delta 4$ or V $\delta 5$ have also been described. $V \delta 2^{+}$cells recognize nonpeptidic phosphorylated metabolites of isoprenoid biosynthetic pathways produced by a variety of bacteria, parasites and some tumor cells, whereas V $\delta 1 \mathrm{~T}$ cells are activated by stress-induced molecules such as MIC-A and MIC-B $[2,3]$.

Several investigations into the phenotypic and functional alterations of $\gamma \delta$ T-cells in the human aging process have been initiated in the last few years, some demonstrating a decrease in $\gamma \delta$ T-cell numbers with age, mainly due to declining numbers of the $V \delta 2^{+}$subset, with the V $\delta 1$ population remaining stable [4-8]. There is also one publication demonstrating a decrease in naïve and early differentiated cells and an increase in late differentiated $\gamma \delta$ T-cells in men but not in women [7]. Many similar age-

\section{Biomed Central}


associated changes described in $\alpha \beta$ T-cells, particularly the accumulation of late-differentiated CD8 T-cells, have been attributed to a latent infection with human Cytomegalovirus (CMV) and not chronological age [9-11]. CMV is a ubiquitous beta-herpes virus causing mostly asymptomatic infection in healthy individuals. After the first infection, the virus enters cellular latency, but can reactivate repeatedly under different conditions [12]. Both CD4 and CD8 $\alpha \beta$ T-cells are involved in anti-CMV immune surveillance. In fact a large fraction of these cells can be specific for this single virus [13], which can lead to an accumulation of late-differentiated CD8 T-cells, reciprocated by a decrease in naïve T-cells [14]. $\gamma \delta \mathrm{T}$-cells have also been implicated in anti-CMV immunity and control of infection [15-18] which is mediated through V $\delta 2^{-}$cells (mainly V $\delta 1$ and V $\delta 3$ but also V $\delta 5[15,18]$ ). Accordingly, CMV-seropositivity has been associated with higher frequencies and absolute numbers of $\mathrm{V} \delta 2^{-}$cells in the periphery $[4,17,19-21]$ and with a more restricted repertoire compared to $\mathrm{V} \delta 2^{+}$cells [19].

The proportion of the population infected with CMV increases steadily with age in Western countries with a seroconversion rate of $1-3 \%$ per year [22] and has been associated with higher morbidity and mortality in some studies $[23,24]$. Whether a latent infection with this virus has any impact on possible age-associated putative changes to the phenotype of $\gamma \delta$ T-cells, as is the case with $\alpha \beta$ $\mathrm{T}$-cells, has not been explored before. Here, we present data demonstrating that similar to $\alpha \beta$ T-cells, age-associated differences in $\gamma \delta$ T-cell frequency and differentiation phenotype are predominantly present in individuals with a latent infection with CMV, but in uninfected people. Additionally, we describe a negative correlation between a more late-differentiated phenotype of $\mathrm{V} \delta 2^{-}$cells and anti-CMV IgG levels in serum, which increased significantly with age in our study cohort.

\section{Results}

Minor impact of age on the frequency and phenotype of $\gamma \delta$ T-cells in the absence of CMV infection

Given the strong impact of CMV-seropositivity on age-associated alterations observed in $\alpha \beta$ T-cells, we sought to determine if the same was true for $\gamma \delta$ T-cells. For this, individuals were grouped according to CMV-serostatus and age, and the frequency and phenotype of $\gamma \delta$ T-cells was compared. In CMV-seropositive individuals we observed a significantly lower ratio of $\mathrm{V} \delta 2^{+} / \mathrm{V} \delta 2^{-}$cells in older individuals (Figure 1A, left-hand panel), as well as a strong age-associated trend towards a reduction in early-differentiated $\mathrm{CD} 27^{+} \mathrm{CD} 28^{+} \mathrm{V} \delta 2^{-} \mathrm{T}$-cells $(\mathrm{p}=0.059)$ reciprocated by a significant accumulation of $\mathrm{CD} 27^{-} \mathrm{CD} 28^{-}$ V $2^{-}$T-cells ( $\left.\mathrm{p}=0.0399\right)$ (Figure $1 \mathrm{~B}$ and $\mathrm{C}$, left-hand graphs). Contrary to the $V \delta 2^{-}$cells, in the $\mathrm{V} \delta 2^{+}$subset, ageing was associated with higher frequency of early-differentiated cells
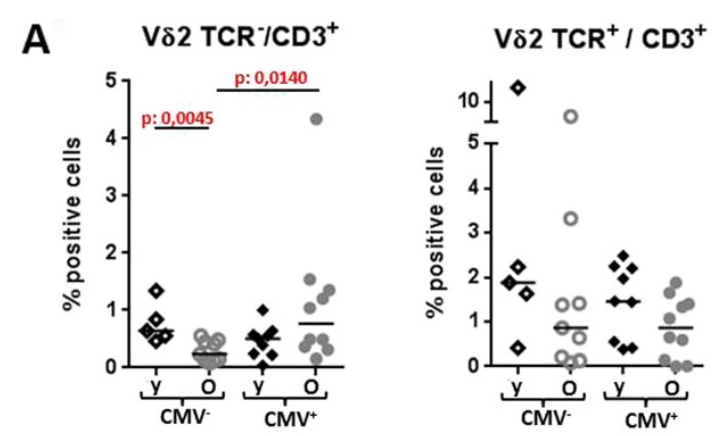

B $\mathrm{CD}_{27^{+}} \mathrm{CD}^{-8^{+}} / \mathrm{V} \delta 2 \mathrm{TCR}^{-}$

$\mathrm{CD}^{+} \mathrm{CDD}^{+} \mathrm{C}^{+} / \mathrm{V} \delta 2 \mathrm{TCR}^{+}$
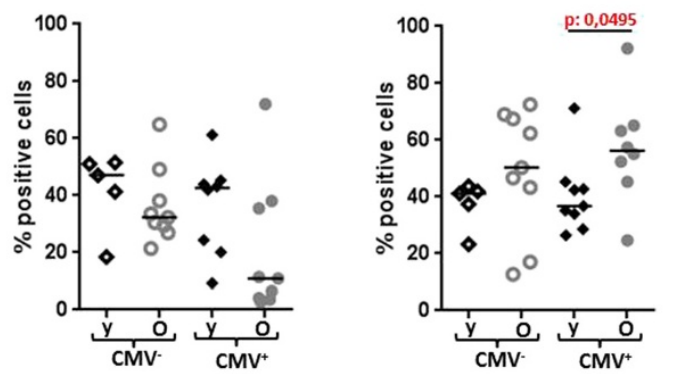

C
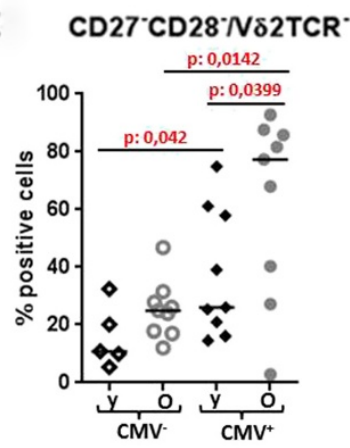

$\mathrm{CD}^{\circ} \mathrm{C}^{\circ} \mathrm{CD} 28^{-} / \mathrm{N} \delta 2 \mathrm{TCR}^{+}$

D
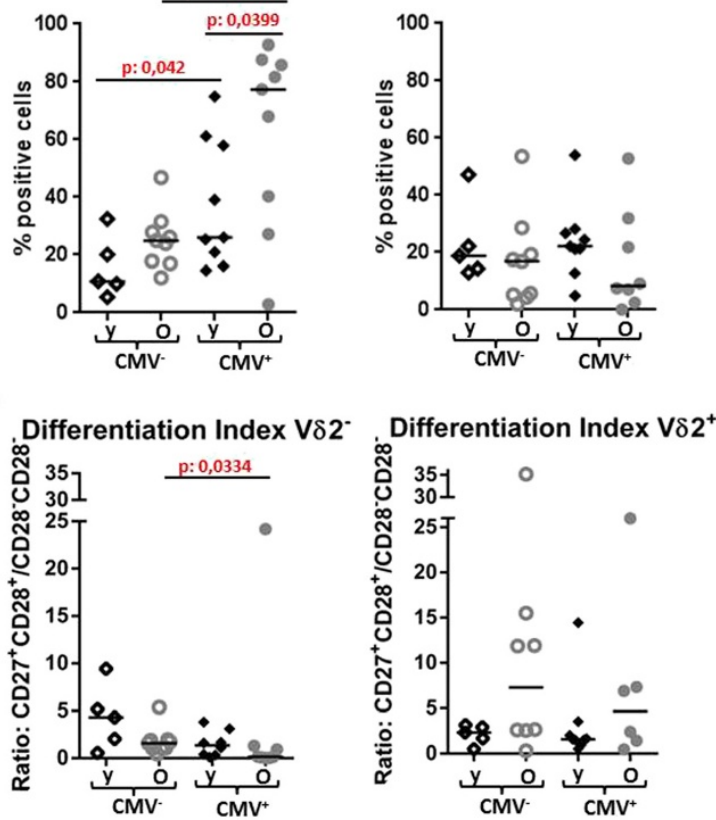

Figure 1 Impact of CMV-serostatus on frequency and differentiation status of $\gamma \delta$ T-cells. The frequency of $V \delta 2^{-}$and $V \delta 2^{+} \gamma \delta$ T-cells within total T-cells (A), CD2 $7^{+} \mathrm{CD} 28^{+}$early-differentiated (B) and CD27 CD28- late-differentiated cells (C) within $\mathrm{V} \delta 2^{+}$and V82 ${ }^{-}$cells as well as the differentiation index $\left(\mathrm{CD}^{2} 7^{+} \mathrm{CD} 28^{+} / \mathrm{CD}^{-} \mathrm{CDD}^{-} \mathrm{C}^{-}\right)$ for each subset (D) were compared between CMV-seronegative (CMV) and $\mathrm{CMV}$-seropositive $\left(\mathrm{CMV}^{+}\right)$individuals between 21 and 89 years of age. Each symbol represents a single donor. Horizontal bars represent the median of the group. P values were calculated using the Mann-Whitney U-test. Y: young 21 to 38 years, 10 female, 4 male; O: old, 55 to 89 years, 11 female, 8 male). 
(Figure 1B, right-hand panel, $\mathrm{p}=0.049$ ). These differences were absent in CMV-seronegative donors (Figure 1). Here, we only observed a significant reduction of $\mathrm{V} \delta 2^{-}$T-cells (Figure 1A left-hand graph, $\mathrm{p}=0.0045$ ).

\section{CMV-seropositivity is associated with phenotypic differences in $\gamma \delta$ T-cells}

Having established a strong impact of CMV on the manifestation of age-associated changes in the phenotype and frequency of $\gamma \delta$ T-cells, we investigated the impact of a latent infection with CMV on these parameters in young and old CMV-seronegative and CMV-seropositive individuals. We observed a significantly higher proportion of $\mathrm{V}^{-} 2^{-}$ cells in old CMV-seropositive donors $(p=0.014$, Figure $1 \mathrm{~A}$, left-hand graph). Although the differentiation phenotype of the $\mathrm{V} \delta 2^{+}$population was not associated with CMV-seropositivity, strong correlations were observed in the $\mathrm{V} \delta 2^{-}$group. Thus, in old CMV-seropositive donors, there was a trend toward lower proportions of earlydifferentiated cells (Figure 1B, left-hand panel, $\mathrm{p}=0.0 .0934$ ). Significantly higher proportions of late differentiated cells were observed in both young $(\mathrm{p}=0.042)$ and old $(\mathrm{p}=0.0142)$ CMV-seropositive donors compared to age-matched CMV-seronegative individuals (Figure 1C, left-hand graphs). Accordingly, the differentiation index of $\mathrm{V} \delta 2^{-}$ cells (the ratio between the two early and late differentiated phenotypes) was lower in CMV-seropositive donors (Figure 1D, left-hand panel, $\mathrm{p}=0.0334$ for the old and $\mathrm{p}=0.0653$ for the young).

Confirming our findings at the population level, we observed a more late-differentiated phenotype of $\mathrm{V} \delta 2^{-}$ $\mathrm{T}$-cells compared to $\mathrm{V} \delta 2^{+} \mathrm{T}$-cells within each individual. In the majority of CMV-seropositive donors, the $\mathrm{V} \delta 2^{-}$subset contained a lower proportion of the early-differentiated $\mathrm{CD} 27^{+} \mathrm{CD} 28^{+}$phenotype ( $\mathrm{p}=0.0554$, Figure $2 \mathrm{~A}$, right-hand panel) and a significantly higher proportion of the latedifferentiated $\mathrm{CD} 27^{-} \mathrm{CD} 28^{-}$phenotype $(\mathrm{p}=0.0042$, Figure $2 \mathrm{~B}$, right-hand panel) compared to the $\mathrm{V} \delta 2^{+}$subsets. This was not observed in CMV-seronegative donors (Figure 2, left-hand panels).

\section{Anti CMV-IgG titers rise with age and correlate with the differentiation status of $\gamma \delta$ T-cells}

In an attempt to elucidate the reason behind a strong impact of CMV on age-associated differences in $\gamma \delta$ $\mathrm{T}$-cells, we performed a correlation analysis between age and anti-CMV IgG titers. In our cohort, increasing age was associated with higher levels of anti-CMV IgG in serum $(r=0.5320, p=0.019)$. For this reason and also considering the large heterogeneity of CMV-seropositive donors for some of the variables shown in Figure 1, we asked whether the level of anti-CMV IgG correlated with particular $\gamma \delta$ T-cell subsets and phenotypes. We found a significant decrease in the $\mathrm{V} \delta 2^{+} / \mathrm{V} \delta 2^{-}$ratio $(\mathrm{r}=-0.5170$,

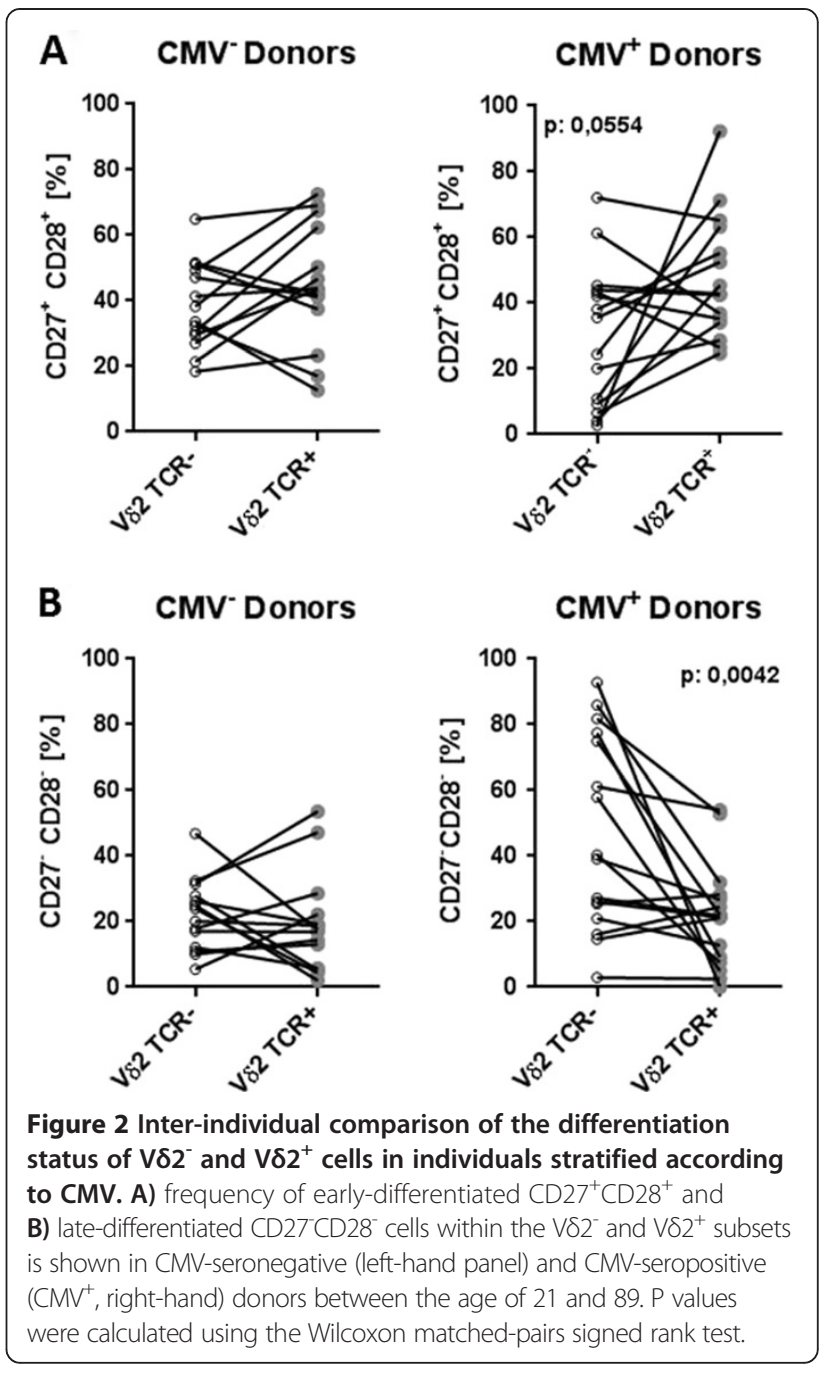

$\mathrm{p}=0.028$ ) with increasing titer, whereas the latter parameter did not correlate directly with the frequency of cells expressing the $\mathrm{V} \delta 2^{+}$receptor or lacking it (Figure 3A). Significant correlations were observed between the differentiation status of V $\delta 2^{-}$T-cells and anti-CMV IgG titer: the latter correlated negatively with the frequency of early differentiated $(r=-0.5245, p=0.0327$, Figure 3B, left-hand panel) and positively with the frequency of late differentiated $\left(r=0.5996, p=0.0085\right.$, Figure $3 C$, left-hand panel) $V \delta 2^{-}$ T-cells. Accordingly, the differentiation index of $\mathrm{V} \delta 2^{-}$ cells decreased with rising CMV-specific IgG titers $(\mathrm{r}=-0.5912, \mathrm{p}=0.0288)$. There was no correlation between the differentiation status of $\mathrm{V} \delta 2^{+} \mathrm{T}$-cells and CMV-specific IgG titers (Figure $3 \mathrm{~B}$ and $\mathrm{C}$, right-hand panels).

\section{Discussion}

This study demonstrates for the first time that ageassociated differences in $\gamma \delta \mathrm{T}$-cell populations are marked only in individuals with a latent CMV infection. Several studies have reported a decrease in the counts and 


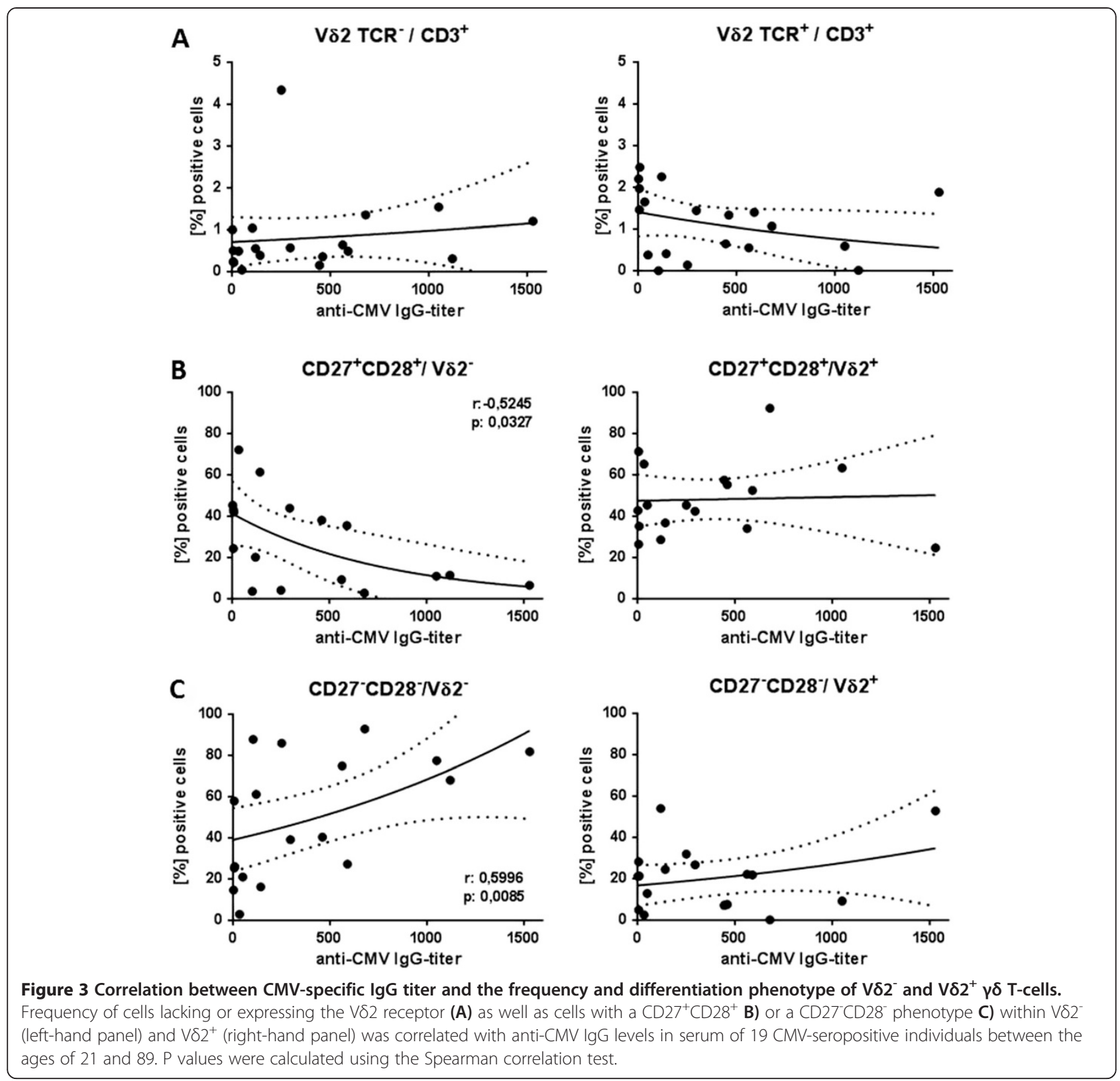

frequencies of $\gamma \delta$ T-cells with ageing, which is mainly due to the reduction in the $\mathrm{V} \delta 2^{+}$subset [4-8]. We also observed a trend towards age-associated reduction in the frequency of these cells, statistically significant when CMV-seronegative and -seropositive donors were pooled $(\mathrm{p}=0.01$, data not shown). There was also a significant accumulation of cells with a late-differentiated phenotype of the $V \delta 2^{-} \gamma \delta$ T-cells with increasing age, but only in CMV-seropositive individuals. This is consistent with CMV as a driving force for the accumulation of late-differentiated $\gamma \delta$ T-cells, as is the case for $\mathrm{CD}^{+} \alpha \beta$ T-cells [9-11]. Those data demonstrating no impact of chronological age on reduction of naïve and accumulation of late-differentiated memory CD8 T-cells in CMV-seronegative individuals, therefore also apply to $\mathrm{V} \delta 2^{-}$cells which have been implicated in anti-CMV immunity in several studies [4,15-21]. Thus, the age-associated increase in the differentiation status of these cells in the elderly might be explained by their more frequent encounter with the virus, either due to an earlier time of primary infection and/or more reactivation rounds of the virus, which might take place in the elderly [25]. Since both primary infection and reactivation are usually asymptomatic, it is not possible to determine viral infection and reactivation history with current virological tools. However, we did observe age-associated higher anti-CMV IgG titers in our study, possibly indicating 
greater activity of the immune system against this virus as an individual ages. To the best of our knowledge, this is the first study to show an age-associated difference in the differentiation status of V $\delta 2^{-}$T-cells, whereas the same trend was not seen in $\mathrm{V} \delta 2^{+}$cells, which are not involved in anti-CMV immunity. Two studies have reported a decrease in the frequency of naive-phenotype cells within the $\mathrm{V} \delta 2^{+}$ subset with increasing age $[4,7]$, although this was reported to be limited to men in one study [7]. The discrepancy between our finding and the published data might be due to the overrepresentation of women in our cohort and the use of different surface markers for phenotyping the differentiation status.

Stratifying the donors according to CMV-serostatus revealed significantly higher frequencies of $\mathrm{V} \delta 2^{-} \mathrm{T}$-cells in $\mathrm{CMV}^{+}$older individuals, in line with previously published data indicating expansion of $\mathrm{V} \delta 2^{-}$cells in healthy carriers of the virus $[17,19,20]$ as well as large expansions of these cells in transplant recipients undergoing primary infection with or reactivation of CMV $[15,17,20]$. Moreover, V $\delta 2^{-}$cells in CMV-seropositive individuals had a more late-differentiated phenotype compared to CMV-seronegative individuals, in line with previously published data $[19,20]$, whereas the phenotype of ${\mathrm{V} \delta 2^{+}}^{+}$cells was not affected by a latent infection with CMV. Confirming these findings at the individual level, $\mathrm{V} \delta 2^{-}$cells in CMV-seropositive donors were significantly more late-differentiated compared to $\mathrm{V} \delta 2^{+}$cells from the same donor.

Increasing evidence suggests that not only mere seropositivity for the virus, but the way the immune system is affected by the virus and deals with it, may have implications in healthy ageing and mortality $[10,26]$. Accordingly, not merely the presence of a latent infection with the virus per se, but the level of anti-CMV IgG antibodies in serum has been shown to correlate with all-cause mortality in some studies $[27,28]$. In the present study, we observed a significant correlation between the anti-CMV IgG titer and the differentiation status only of V $2^{-}$T-cells, whereas again no correlation was observed for the $\mathrm{V} \delta 2^{+}$subset. Although similar data are lacking on $\gamma \delta$ T-cells, we have previously shown that individuals with higher anti-CMV IgG titers possess significantly higher frequencies and absolute numbers of late-differentiated $\mathrm{CD}^{+}{ }^{+}$T-cells [29]. High levels of anti-CMV IgG antibody might indicate more activation rounds of the virus thus leading to a more late-differentiated phenotype of CMV-reactive $V \delta 2^{-} \gamma \delta$ T-cells, which may be involved in viral control. Another possible explanation might be a direct stimulation of $\mathrm{V} \delta 2^{-} \mathrm{T}$-cells through anti-CMV IgG and the virus during reactivation rounds. It was elegantly demonstrated in a recent study that late-differentiated V82- T-cells in CMV-seropositive individuals express high levels of CD16 and can be activated by ligation of this receptor through anti-CMV IgG in the presence of the virus [20]. Vice versa, this correlation might be due to a helper role of $\gamma \delta$ T-cells, similar to that of $\mathrm{CD}^{+} \alpha \beta$ T-cells in the induction of a humoral immune response - $\gamma \delta$ T-cells express essential costimulatory molecules such as CD40L, OX40, CD70 and ICOS, when activated in vitro [30]. Further experiments are needed to elucidate the link between high levels of anti-CMV IgG titers and the more late-differentiated phenotype of $\gamma \delta$ T-cells observed in our study.

\section{Conclusions}

The data presented here demonstrate that the strong impact of CMV-infection on $\mathrm{T}$ cell phenotypes generally attributed to chronological ageing of the immune system is not observed exclusively in $\alpha \beta$ T-cells, but analogously to the greater effect on $\alpha \beta$ CD8-vs-CD4 T-cells, is also observed inV $\delta 2^{-} \mathrm{T}$-cells, in line with the involvement of these cells in anti-CMV immunity.

\section{Material and methods Subjects}

Experiments were conducted using blood isolated from healthy volunteers of different ages after appropriate signed informed consent and were approved by the Ethics Commission (IRB protocol \#20070481). The individuals participating in this study were screened for diseases known to alter the immune response or for consumption of medications that could alter the immune response. Volunteers were recruited at the University of Miami, Miller School of Medicine. In every experiment reported in the present paper, 33 healthy donors (21 women and 12 men) between the ages of 21 and 89 years (mean age 51.5 years) were evaluated.

CMV antibody screening was performed using cobas $6000^{\circ}$ e601 analyzer (Roche, Hitachi) with Elecsys CMV assays (Roche Diagnostics, Mannheim, Germany): CMV $\operatorname{IgM}$ ( $\mu$-capture assay, cutoff index $<0.7 ; \geq 1.0$, reactive); CMV IgG (cutoff $<0.5 \mathrm{U} / \mathrm{ml}$; reactive $\geq 1 . .0 \mathrm{U} / \mathrm{ml}$ ), and CMV IgG avidity (< $45.0 \%$, low avidity; 45.0-54,9\%, grey zone; $\geq 55,0 \%$, high avidity). In cases of borderline or positive CMV IgM results a recombinant CMV IgM immunoblot (Mikrogen, Neuried, Germany) was performed for confirmation. To ensure that there was no acute CMV-infection at blood donation, here we analysed only donors who were negative for anti-CMV IGM antibody.

\section{Flow cytometry}

After thawing, cryopreserved peripheral blood mononuclear cells (PBMCs) were first treated with human immunoglobulin, GAMUNEX (Bayer, Leverkusen, Germany) and ethidium monoazide bromide (EMA, MoBiTec Gmbh, Göttingen, Germany) in order to block surface Fc receptors and non-viable cells respectively. The cells were then 
stained indirectly with a monoclonal pan $\gamma \delta$ TCR-antibody (clone: 11F2; BD Pharmingen, Heidelberg, Germany) which was detected via Pacific Orange-labelled Fab2' fragment goat anti-mouse (Live Technologies, Darmstadt, Germany). After blocking with mouse serum (Millipore, Temecula CA, USA), directly conjugated monoclonal antibodies CD3 Alexa Fluor 700 (clone: UCHT-1), CD8 APC-H7 (clone: SK1), CD28 PE (clone: CD28.2) (all from BD Biosciences), CD4 PE-Cy7 (clone: OKT4), CD27 APC (clone: 0323), and anti-V82 TCR PerCP (clone: B6) (all from BioLegend, San Diego, USA) were added for 20 minutes on ice. After washing twice, the cells were measured immediately on an LSR II (BD, Heidelberg). The compensation of the spectral overlap was calculated automatically by BD FACSDiva software, based on the measurement of single colour controls. Data were analysed using FlowJo V 7.6.5 (Tree Star, Portland, USA).

For the analysis, the lymphocyte population was gated in a forward / sideways scatter plot followed by exclusion of duplets in an FSC-height-vs. FSC-width plot. After exclusion of $\mathrm{EMA}^{+}$dead cells, $\mathrm{CD} 4^{-} \mathrm{CD}^{-}$cells were gated within the $\mathrm{CD}^{+}$gate and used as starting populations to analyse $\gamma \delta$ T-cells, which were characterised as $\gamma \delta^{+} \mathrm{V} \delta 2^{+}$ or $\gamma \delta^{+} \mathrm{V} \delta 2^{-}$. The latter populations were further studied for $\mathrm{CD} 27$ and CD28 expression to determine their differentiation phenotype (see Additional file 1 for the gating strategy). All parental populations $<120$ counts were excluded from further analysis. Data analysis and flow cytometry staining were performed on blinded samples.

\section{Statistical analysis}

Statistical analysis was performed using GraphPad V6 (GraphPad Software, Inc., La Jolla, USA). For comparisons between two independent groups the Mann-Whitney $\mathrm{U}$ Test was used. Correlation between two continuous variables was analyzed using the Spearman-Person Test. Comparisons between two variables within each individual were performed using the Wilcoxon matched-pairs signed rank test. P-values $<0.05$ were considered significant.

\section{Additional file}

Additional file 1: Gating-strategy for $\gamma \delta \mathrm{T}$-cell frequency and differentiation phenotype. Flow cytometry plots representing the gating strategy used for characterisation of $\gamma \delta$ T-cells and their differentiation phenotype.

\section{Abbreviations}

CD: Cluster of differentiation; CMV: Cytomegalovirus; EMA: Ethidium monobromide azide; ICOS: Inducible T-cell Costimulator; Ig: Immunoglobulin; TCR: T-cell receptor.

\section{Competing interests}

The authors declare no competing interests.

\section{Authors' contributions}

KWH was involved in data acquisition, analysis and interpretation as well as drafting the manuscript. GP and ED were involved in designing the experiments, analysis and interpretation of data and drafting the manuscript. DF and BB were involved in recruiting the individuals participating in the study, discussion of the data obtained and writing of the manuscript.

All authors have approved the final version.

\section{Acknowledgements}

We would like to thank Prof. Klaus Hamprecht and Ms Wioleta Kapis (Department of Medical Virology, University Clinic Tübingen) for performing the CMV-serology; Karin Hähnel for assistance in processing the samples and Lilly Oettinger for antibody titration and flow cytometry quality control. This work was supported by the German Research Foundation [DFG-PA 361/141], the German Federal Ministry of Education and Research (BMBF) under grant numbers 0315890F, "Gerontoshield" and 16SV5536K, "BASE-II", the European Commission [FP7 259679 "IDEAL"] and by NIH grant AG-32576 (BBB). Responsibility for the contents of this publication lies with the authors. The funding sources were not involved in study design; in the collection, analysis and interpretation of data; in the writing of the report; and in the decision to submit the article for publication.

\section{Author details}

${ }^{1}$ Department of Internal Medicine II, Centre for Medical Research, University of Tübingen, Tübingen, Germany. ${ }^{2}$ Department of Microbiology and Immunology, University of Miami Miller School of Medicine, Miami, FL, USA.

Received: 10 December 2012 Accepted: 29 June 2013

Published: 3 July 2013

\section{References}

1. Deusch K, Luling F, Reich K, Classen M, Wagner H, Pfeffer K: A major fraction of human intraepithelial lymphocytes simultaneously expresses the gamma/delta T cell receptor, the CD8 accessory molecule and preferentially uses the V delta 1 gene segment. Eur J Immunol 1991, 21:1053-1059.

2. Groh V, Steinle A, Bauer S, Spies T: Recognition of stress-induced MHC molecules by intestinal epithelial gammadelta T cells. Science 1998, 279:1737-1740.

3. Vantourout $P$, Hayday A: Six-of-the-best: unique contributions of gammadelta T cells to immunology. Nat Rev Immunol 2013, 13:88-100.

4. Michishita Y, Hirokawa M, Guo YM, Abe Y, Liu J, Ubukawa K, Fujishima N Fujishima M, Yoshioka T, Kameoka Y, et al: Age-associated alteration of gammadelta T-cell repertoire and different profiles of activation-induced death of Vdelta1 and Vdelta2 T cells. Int J Hematol 2011, 94:230-240.

5. Cairo C, Armstrong CL, Cummings JS, Deetz CO, Tan M, Lu C, Davis CE, Pauza CD: Impact of age, gender, and race on circulating gammadelta $T$ cells. Hum Immunol 2010, 71:968-975.

6. Argentati K, Re F, Donnini A, Tucci MG, Franceschi C, Bartozzi B, Bernardini G, Provinciali M: Numerical and functional alterations of circulating gammadelta T lymphocytes in aged people and centenarians. J Leukoc Biol 2002, 72:65-71.

7. Caccamo N, Dieli F, Wesch D, Jomaa H, Eberl M: Sex-specific phenotypical and functional differences in peripheral human Vgamma9/Vdelta2 $\mathrm{T}$ cells. J Leukoc Biol 2006, 79:663-666.

8. Andreu-Ballester JC, Garcia-Ballesteros C, Benet-Campos C, Amigo V, Almela-Quilis A, Mayans J, Ballester F: Values for alphabeta and gammadelta T-lymphocytes and CD4+, CD8+, and CD56+ subsets in healthy adult subjects: assessment by age and gender. Cytometry B Clin Cytom 2012, 82:238-244.

9. Chidrawar S, Khan N, Wei W, McLarnon A, Smith N, Nayak L, Moss P: Cytomegalovirus-seropositivity has a profound influence on the magnitude of major lymphoid subsets within healthy individuals. Clin Exp Immunol 2009, 155:423-432.

10. Derhovanessian E, Maier AB, Beck R, Jahn G, Hahnel K, Slagboom PE, de Craen AJ, Westendorp RG, Pawelec G: Hallmark features of immunosenescence are absent in familial longevity. J Immunol 2010, 185:4618-4624.

11. Looney RJ, Falsey A, Campbell D, Torres A, Kolassa J, Brower C, McCann R, Menegus M, McCormick K, Frampton M, et al: Role of cytomegalovirus in the T cell changes seen in elderly individuals. Clin Immunol 1999, 90:213-219. 
12. Boeckh M, Geballe AP: Cytomegalovirus: pathogen, paradigm, and puzzle. J Clin Invest 2011, 121:1673-1680.

13. Sylwester AW, Mitchell BL, Edgar JB, Taormina C, Pelte C, Ruchti F, Sleath PR, Grabstein KH, Hosken NA, Kern F, et al: Broadly targeted human cytomegalovirus-specific CD4+ and CD8+ T cells dominate the memory compartments of exposed subjects. J Exp Med 2005, 202:673-685.

14. Pawelec $\mathrm{G}$, Derhovanessian $\mathrm{E}$ : Role of $\mathrm{CMV}$ in immune senescence. Virus Res 2011, 157:175-179.

15. Dechanet J, Merville P, Lim A, Retiere C, Pitard V, Lafarge X, Michelson S, Meric C, Hallet MM, Kourilsky P, et al: Implication of gammadelta T cells in the human immune response to cytomegalovirus. J Clin Invest 1999, 103:1437-1449.

16. Lafarge X, Merville P, Cazin MC, Berge F, Potaux L, Moreau JF, Dechanet-Merville J: Cytomegalovirus infection in transplant recipients resolves when circulating gammadelta T lymphocytes expand, suggesting a protective antiviral role. $J$ Infect Dis 2001, 184:533-541.

17. Knight A, Madrigal AJ, Grace S, Sivakumaran J, Kottaridis P, Mackinnon S, Travers PJ, Lowdell MW: The role of Vdelta2-negative gammadelta T cells during cytomegalovirus reactivation in recipients of allogeneic stem cell transplantation. Blood 2010, 116:2164-2172.

18. Halary F, Pitard V, Dlubek D, Krzysiek R, de la Salle H, Merville P, Dromer C, Emilie D, Moreau JF, Dechanet-Merville J: Shared reactivity of V\{delta\}2 (neg) gamma\}\{delta T cells against cytomegalovirus-infected cells and tumor intestinal epithelial cells. J Exp Med 2005, 201:1567-1578.

19. Pitard V, Roumanes D, Lafarge X, Couzi L, Garrigue I, Lafon ME, Merville P, Moreau JF, Dechanet-Merville J: Long-term expansion of effector/memory Vdelta2-gammadelta T cells is a specific blood signature of CMV infection. Blood 2008, 112:1317-1324.

20. Couzi L, Pitard V, Sicard X, Garrigue I, Hawchar O, Merville P, Moreau JF, Dechanet-Merville J: Antibody-dependent anti-cytomegalovirus activity of human gammadelta T cells expressing CD16 (FcgammaRllla). Blood 2012, 119:1418-1427.

21. Willcox CR, Pitard V, Netzer S, Couzi L, Salim M, Silberzahn T, Moreau JF, Hayday AC, Willcox BE, Dechanet-Merville J: Cytomegalovirus and tumor stress surveillance by binding of a human gammadelta $\mathrm{T}$ cell antigen receptor to endothelial protein C receptor. Nat Immunol 2012, 13:872-879.

22. Hecker M, Qiu D, Marquardt K, Bein G, Hackstein H: Continuous cytomegalovirus seroconversion in a large group of healthy blood donors. Vox Sang 2004, 86:41-44

23. Simanek AM, Dowd JB, Pawelec G, Melzer D, Dutta A, Aiello AE: Seropositivity to cytomegalovirus, inflammation, all-cause and cardiovascular disease-related mortality in the United States. PLoS One 2011, 6:e16103.

24. Pawelec G, McElhaney JE, Aiello AE, Derhovanessian E: The impact of CMV infection on survival in older humans. Curr Opin Immunol 2012, 24:507-511.

25. Stowe RP, Kozlova EV, Yetman DL, Walling DM, Goodwin JS, Glaser R: Chronic herpesvirus reactivation occurs in aging. Exp Gerontol 2007, 42:563-570.

26. Derhovanessian E, Maier AB, Hahnel K, Zelba H, de Craen AJ, Roelofs H, Slagboom EP, Westendorp RG, Pawelec G: Lower proportion of naive peripheral CD8+ T cells and an unopposed pro-inflammatory response to human Cytomegalovirus proteins in vitro are associated with longer survival in very elderly people. Age 2012. Jun 4 [Epub ahead of print].

27. Roberts ET, Haan MN, Dowd JB, Aiello AE: Cytomegalovirus antibody levels, inflammation, and mortality among elderly Latinos over 9 years of follow-up. Am J Epidemiol 2010, 172:363-371.

28. Strandberg TE, Pitkala KH, Tilvis RS: Cytomegalovirus antibody level and mortality among community-dwelling older adults with stable cardiovascular disease. JAMA 2009, 301:380-382.

29. Derhovanessian E, Maier AB, Hahnel K, Beck R, de Craen AJ, Slagboom EP, Westendorp RG, Pawelec G: Infection with cytomegalovirus but not herpes simplex virus induces the accumulation of late-differentiated CD4+ and CD8+ T-cells in humans. J Gen Virol 2011, 92:2746-2756

30. Brandes M, Willimann K, Lang AB, Nam KH, Jin C, Brenner MB, Morita CT, Moser B: Flexible migration program regulates gamma delta T-cell involvement in humoral immunity. Blood 2003, 102:3693-3701.

doi:10.1186/1742-4933-10-26

Cite this article as: Wistuba-Hamprecht et al: Age-associated alterations in $\gamma \delta$ T-cells are present predominantly in individuals infected with Cytomegalovirus. Immunity \& Ageing 2013 10:26.

\section{Submit your next manuscript to BioMed Central and take full advantage of:}

- Convenient online submission

- Thorough peer review

- No space constraints or color figure charges

- Immediate publication on acceptance

- Inclusion in PubMed, CAS, Scopus and Google Scholar

- Research which is freely available for redistribution 